\title{
Microstructure Characterization by X-Ray Computed Tomography of C/C-SiC Ceramic Composites Fabricated with Different Carbon Fiber Architectures
}

\author{
Fan Wan ${ }^{1} \cdot$ Talha J. Pirzada ${ }^{2} \cdot$ Rongjun Liu $^{1} \cdot$ Yanfei Wang ${ }^{1} \cdot$ Changrui Zhang $^{1} \cdot$ \\ Thomas James Marrow ${ }^{2}$ (D)
}

Received: 8 March 2019 / Accepted: 4 June 2019 / Published online: 19 June 2019

(C) The Author(s) 2019

\begin{abstract}
The microstructure morphologies have been characterized by high resolution laboratory X-ray computed tomography in Carbon Fiber Reinforced Carbon and Silicon Carbide (C/C-SiC) ceramic composites fabricated by Gaseous Silicon Infiltration (GSI) from C/C preforms of three different architectures: 3D stitched cloth fabric; 3D orthogonal woven fabric; and needled short-cut felt. Each composites' microstructure was influenced by the structure of the $\mathrm{C} / \mathrm{C}$ preform. By incorporating tomography with gravimetric analysis, the $3 \mathrm{D}$ distribution of the $\mathrm{SiC}$ was visualized, showing a connected $\mathrm{SiC}$ network in the needled short-cut felt, and more heterogeneous $\mathrm{SiC}$ formation on the surfaces of the fiber bundles in the stitched and woven fabrics. The needled short-cut felt provided the largest contact surface for the GSI reaction and generated $\sim 56 \%$ volume fraction of $\mathrm{SiC}$, which is almost twice and three times that achieved in the stitched and woven fabrics respectively. Differences in the open and closed pore distributions were also measured by mercury intrusion porosimetry and tomography.
\end{abstract}

Keywords Carbon fiber architecture $\cdot \mathrm{C} / \mathrm{C}$-SiC composite $\cdot$ Microstructure characterization $\mathrm{X}$-ray computed tomography $\cdot$ Mercury intrusion porosimetry

\section{Introduction}

Carbon fiber reinforced carbon and silicon carbide composites (C/C-SiC) have gained widespread attention in aerospace structural systems [1] and advanced friction systems [2] due to their superior mechanical properties under normal and high temperatures [3-5], oxidation and

Thomas James Marrow

james.marrow@materials.ox.ac.uk

1 College of Aerospace Science and Engineering, National University of Defense Technology, Changsha 410073, China

2 Department of Materials, University of Oxford, Oxford OX1 3PH, UK 
ablation resistance [6, 7], and good friction and wear characteristics [8, 9]. Developments in these applications will place higher requirements on these materials, and there is a need to find effective ways to improve their properties. A universally recognized method to optimize material properties is through the control of microstructure [10-12]. However, C/C-SiC composites have complex three-dimensional spatially distributed structures that contain varying fractions of residual $\mathrm{C}$, formed $\mathrm{SiC}$, residual $\mathrm{Si}$ and porosity, which depend on the original carbon fiber architectures and fabrication conditions. Conventional two-dimensional imaging techniques such as optical and scanning electron microscopy (SEM) can only provide very limited information of the $3 \mathrm{D}$ phase structure, and porosity characterization methods such as density measurement by the Archimedes principle (AP) and mercury intrusion porosimetry (MIP) cannot detect the closed pore structure.

$\mathrm{X}$-ray computed tomography (XCT) is a relatively novel method for 3D microstructure characterization of bulk materials, using synchrotron or laboratory X-ray microscopes. Compared with conventional 2D characterization methods, XCT can provide accurate and high resolution $3 \mathrm{D}$ observations of the microstructure, while avoiding the possible introduction of manual damage during the sample preparation process. Consequently, XCT as an advanced non-destructive technique has been applied to a wide range of materials, including wood [13], concrete [14], gypsum [15], graphite [16, 17] and polymer composites [18]. Various ceramic matrix composites [19-23] have also been investigated, but only a few studies have examined C/C-SiC composites [24-27].

In this work $\mathrm{C} / \mathrm{C}$-SiC composites that have been fabricated from different $\mathrm{C} / \mathrm{C}$ preforms, which represent three typical carbon fiber architectures. These are a 3D stitched cloth fabric, a 3D orthogonal woven fabric and a needled short-cut felt, and the composites were fabricated from these preforms by the gaseous silicon infiltration (GSI) method. The microstructure morphologies of the $\mathrm{C} / \mathrm{C}$ preforms and $\mathrm{C} / \mathrm{C}$-SiC composites have been visualized by high resolution laboratory $\mathrm{XCT}$, and together with more conventional characterization by gravimetric analysis and mercury intrusion, their differences of material composition and porosity are considered. These observations are intended to provide useful references in material design and processing. The data may also be the platform for image-based modelling, which can be validated by in situ XCT observations that explore the relationship between microstructure and material performance $[23,28]$.

\section{Materials and Characterization Methods}

The three $\mathrm{C} / \mathrm{C}$ preforms with different architectures of carbon fiber (T-300, fiber density $1.76 \mathrm{~g} / \mathrm{cm}^{3}$ [29]) were: (1) 3D stitched cloth fabric; (2) 3D orthogonal woven fabric; and (3) needled short-cut felt. By their design, these preforms have fiber volume fractions between $50 \%$ to $65 \%$ (Table 1). The preforms were used as the reinforcement for $\mathrm{C} / \mathrm{C}$ $\mathrm{SiC}$ composites. The stitched and woven fabrics were first infiltrated by pyrolytic carbon (PyC) for $80 \mathrm{~h}$ through chemical vapor infiltration (CVI) [30] to achieve final densities of $1.21 \mathrm{~g} / \mathrm{cm}^{3}$ and $1.35 \mathrm{~g} / \mathrm{cm}^{3}$ respectively. The needled short-cut felt was infiltrated by $\mathrm{CVI}$ for $60 \mathrm{~h}$ to a density of $1.10 \mathrm{~g} / \mathrm{cm}^{3}$. The $\mathrm{C} / \mathrm{C}$-SiC composites were prepared from the three preforms by gaseous silicon infiltration (GSI) [31] at $1700{ }^{\circ} \mathrm{C}$ for $2 \mathrm{~h}$, and achieved final densities in composites (1), (2) and (3) of $2.37 \mathrm{~g} / \mathrm{cm}^{3}, 2.16 \mathrm{~g} / \mathrm{cm}^{3}$ and $2.61 \mathrm{~g} / \mathrm{cm}^{3}$ respectively (Table 2 ). 
Table 1 Densities and fiber contents of the $\mathrm{C} / \mathrm{C}$ preform architectures. Average values \pm sample standard deviation $(n=3)$. Preform densities measured by Archimedes principle (AP). Carbon content measured by segmentation of X-ray computed tomographs (XCT). Theoretical densities calculated using T-300 carbon fiber density of $1.76 \mathrm{~g} \mathrm{~cm}^{-3}$ [29]

\begin{tabular}{|c|c|c|c|c|c|}
\hline \multirow[t]{2}{*}{ Architecture } & \multicolumn{2}{|l|}{ Before CVI } & \multicolumn{3}{|l|}{ After CVI } \\
\hline & $\begin{array}{l}\text { Fiber volume } \\
\text { fraction }(\%)\end{array}$ & $\begin{array}{l}\text { Theoretical } \\
\text { Density } \\
\left(\mathrm{g} \mathrm{cm}^{-3}\right)\end{array}$ & $\begin{array}{l}\text { Measured } \\
\text { density } \\
(\mathrm{AP})\left(\mathrm{g} \mathrm{cm}^{-3}\right)\end{array}$ & $\begin{array}{l}\text { Carbon } \\
\text { content } \\
(\mathrm{XCT})(\mathrm{Vol} \%)\end{array}$ & $\begin{array}{l}\text { Theoretical } \\
\text { Density } \\
(\mathrm{XCT})\left(\mathrm{g} \mathrm{cm}^{-3}\right)\end{array}$ \\
\hline 3D stitched cloth fabric: (1) & 55 & 0.97 & $1.21 \pm 0.05$ & 69.7 & 1.23 \\
\hline 3D orthogonal woven fabric: (2) & 65 & 1.15 & $1.35 \pm 0.08$ & 76.8 & 1.35 \\
\hline Needled short-cut felt: (3) & 50 & 0.88 & $1.10 \pm 0.04$ & 63.0 & 1.11 \\
\hline
\end{tabular}

The densities of the preforms and composites were measured in kerosene by the standard Archimedes principle:

$$
\rho=\frac{m_{1}}{m_{3}-m_{2}} \rho_{k}
$$

where $\rho$ is the density of the tested sample, $\rho_{k}=0.8 \mathrm{~g} / \mathrm{cm}^{3}$ is the density of kerosene at room temperature, $m_{1}$ is the dry weight of sample, $m_{2}$ is the submerged weight of the sample after full impregnation in kerosene and $m_{3}$ is the wet weight of sample on removal from kerosene after full impregnation, with the liquid on sample surface wiped off. The materials were fabricated at the Laboratory of Science and Technology on Advanced Ceramic Fibers and Composites at the National University of Defense Technology (China). The fabricated materials were plates, $50 \mathrm{~mm} \times 50 \mathrm{~mm}$ in length and width, with thicknesses of $7 \mathrm{~mm}, 5.5 \mathrm{~mm}$ and $6 \mathrm{~mm}$ respectively for $\mathrm{C} / \mathrm{C}-\mathrm{SiC}$ composites (1), (2) and (3).

The open porosity of the composites was measured by mercury intrusion porosimetry, using an AutoPore IV9510 Hg-porosimeter (Micromeritics) at Nanjing Forestry University. The tested coupons had dimensions of $3.8 \mathrm{~mm} \times 10 \mathrm{~mm} \times 4 \mathrm{~mm}, 4.6 \mathrm{~mm} \times 10 \mathrm{~mm} \times 4 \mathrm{~mm}$ and $7 \mathrm{~mm} \times 10 \mathrm{~mm} \times 4 \mathrm{~mm}$, and weights of $0.36 \mathrm{~g}, 0.40 \mathrm{~g}$ and $0.73 \mathrm{~g}$, for architectures (1), (2) and (3) respectively. Gravimetric analysis (GA) [32] was applied to measure the phase contents of the composites using samples with dimensions of $2 \mathrm{~mm} \times 4 \mathrm{~mm} \times 10 \mathrm{~mm}$. The volume fractions of $\mathrm{Si}\left(V_{S i} \%\right), \mathrm{C}\left(V_{C} \%\right)$ and $\mathrm{SiC}\left(V_{S i C} \%\right)$ were calculated as:

$$
\begin{gathered}
V_{S i} \%=\frac{\left(M_{1}-M_{2}\right) \rho_{C / C-S i C}}{M_{1} \rho_{S i}} \times 100 \% \\
V_{C} \%=\frac{\left(M_{2}-M_{3}\right) \rho_{C / C-S i C}}{M_{1} \rho_{C}} \times 100 \% \\
V_{S i C} \%=\frac{M_{3} \rho_{C / C-S i C}}{M_{1} \rho_{S i C}} \times 100 \%
\end{gathered}
$$

where: $M_{1}$ is the initial dry weight of the sample; $M_{2}$ is its dry weight after immersion in a mixture of nitric and hydrofluoric acids $\left(\mathrm{HNO}_{3}: \mathrm{HF}=4: 1\right)$ at $40{ }^{\circ} \mathrm{C}$ for $48 \mathrm{~h}$ to dissolve residual silicon; $M_{3}$ is the dry weight after then heating in a muffle furnace at $800{ }^{\circ} \mathrm{C}$ for $6 \mathrm{~h}$ to oxidise 


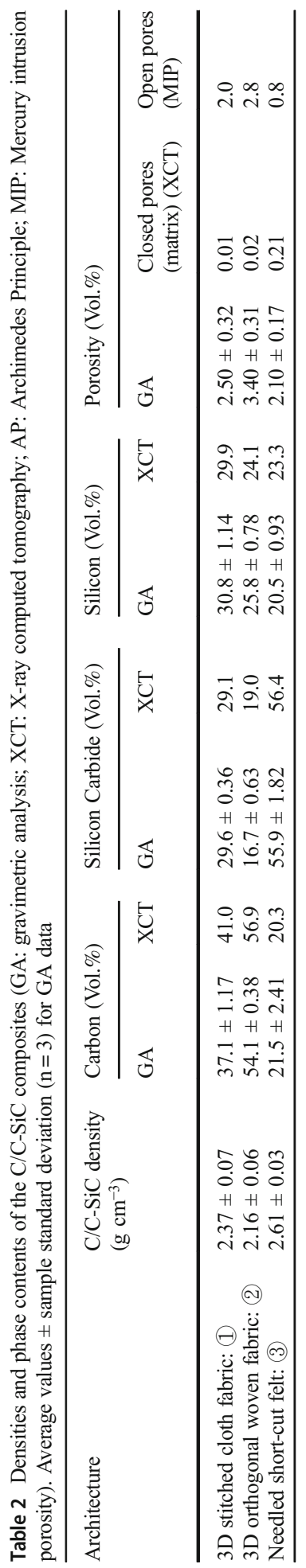


the carbon. The initial measured density of the composite is $\rho_{C / C-S i C}$, and the theoretical densities of $\beta-\mathrm{SiC}\left(\rho_{S i C}\right)$ and $\mathrm{Si}\left(\rho_{S i}\right)$ are $3.20 \mathrm{~g} / \mathrm{cm}^{3}$ and $2.33 \mathrm{~g} / \mathrm{cm}^{3}$ respectively. The carbon density (assumed for both fibers and $\mathrm{PyC}$ ), $\rho_{C}$, is $1.76 \mathrm{~g} / \mathrm{cm}^{3}$ [29]. The total porosity $(P)$ of the tested sample, obtained by gravimetric analysis is:

$$
P=1-V_{S i} \%-V_{C} \%-V_{S i C} \%
$$

Samples of the $\mathrm{C} / \mathrm{C}$ preforms and the $\mathrm{C} / \mathrm{C}$-SiC composites, cut by wire electrical discharge machining (WEDM), were examined by X-ray tomography. This was done using an Xradia Versa 510 X-ray microscope at Oxford University (Department of Materials), operated at $80 \mathrm{keV}$ energy and $7 \mathrm{~W}$ power with 1600 radiographic projections obtained over a $360^{\circ}$ rotation at an exposure time of $2 \mathrm{~s}$ per projection. The voxel dimension in the reconstructed tomographs was $7 \mu \mathrm{m}$, with a visualized volume that was a cylinder of 1012 voxel height and 980 voxel radius (i.e. $\sim 7 \mathrm{~mm}$ ). The microscope software was used for the sample reconstruction, with visualization by the Avizo 9.3.0 software.

\section{Results}

\subsection{C/C Preform Microstructures}

Tomograph slices of the $\mathrm{C} / \mathrm{C}$ preforms $(x-y$ and $y-z$ planes $)$ are presented in Fig. 1 . The architecture of preform (1) (Fig. 1a) shows the cross-woven horizontal fiber bundles $\left(0^{\circ}\right.$ and $90^{\circ}$ ) have a significant irregularity in their array, and the locking stitch sutures ( $z$-direction fiber bundle) are surrounded by large pores. Preform (2) (Fig. 1b) has an architecture of regularly arranged $0^{\circ} / 90^{\circ}$ fiber bundles in the $x-y$ plane, separated by regularly arranged pores connected via small throats that surround the interpenetrating ( $z$-direction) fiber bundles. Some structural defects can be observed, such as a missing horizontal fiber bundle that is labelled as Point A in Fig. 1b (i). The preform of architecture (3) has a typical felt structure with relatively uniform distributions of fibers and pores. 3D reconstructions of $\mathrm{C} / \mathrm{C}$ preforms and their porosity, labeled by simple threshold segmentation (Hounsfield greyscale level), are shown in Fig. 2.

The porosity in architectures (1) and (2) is quite heterogeneously distributed while the porosity of architecture (3) appears more homogeneous. The proportion of the volume that is occupied by carbon in the XCT images of the preforms (measured by segmentation) has been used to calculate the theoretical density, assuming the density of T-300 carbon fiber $\left(1.76 \mathrm{~g} \mathrm{~cm}^{-3}\right)$ [29] is representative of both fibers and the CVI-deposited PyC. The results are quite consistent with the densities measured by the Archimedes principle (Table 1), which supports the reliability of the image segmentation of the carbon preforms. The theoretical densities predicted from the designed fiber content of the three architectures (i.e. between $50 \%$ to $65 \%$ by volume) are also summarized in Table 1 to illustrate the density increase that is due to the CVI-deposited PyC.

\subsection{C/C-SiC Composite Microstructures}

Regions of the 3D volume reconstructions of the C/C-SiC composites are shown in Fig. 3. These have been cropped to display the central region of each sample. Due to differences in electron density that determine the X-ray attenuation of each phase, the $\mathrm{SiC} / \mathrm{Si}$ matrix has the 


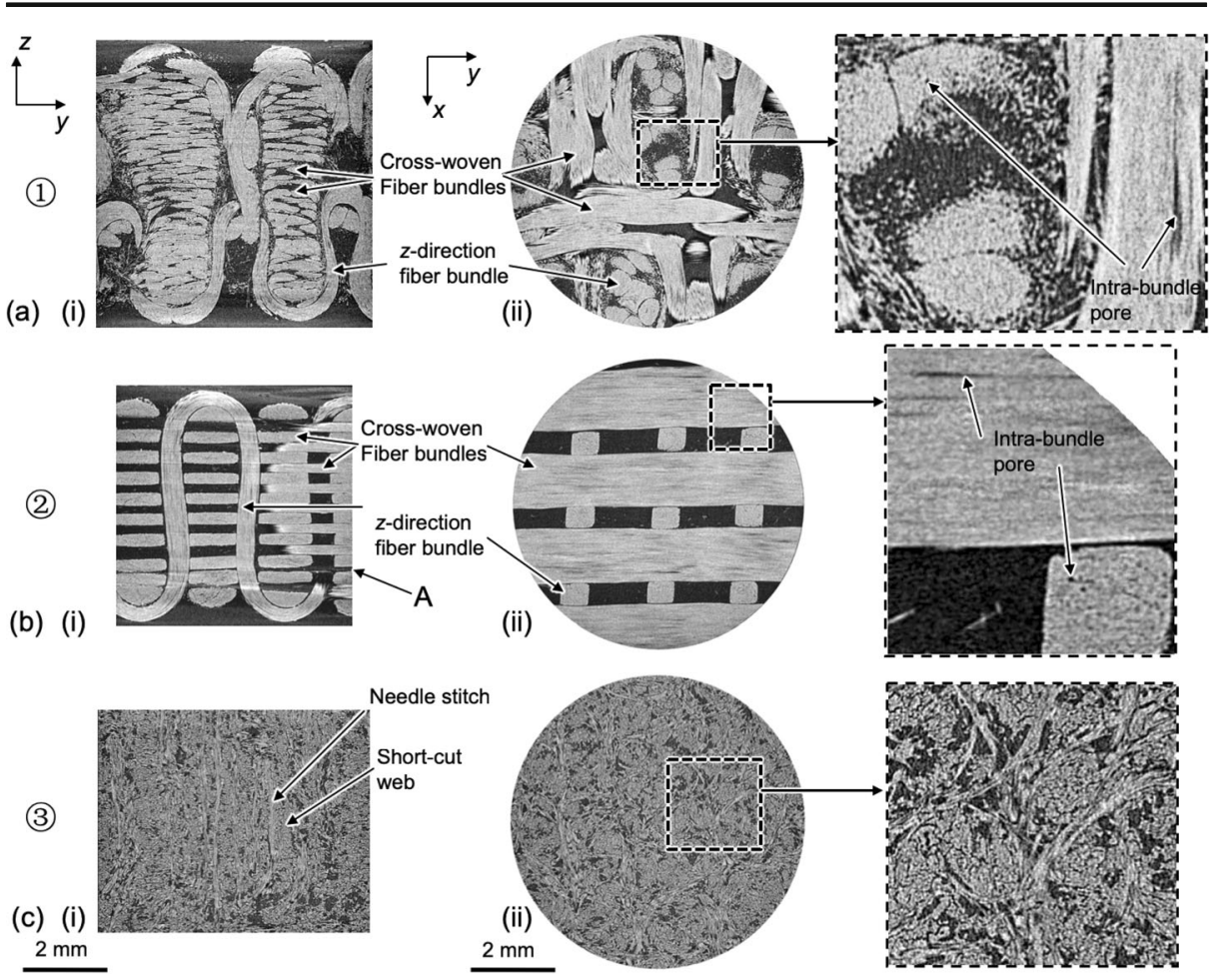

Fig. 1 Tomography slices of the C/C preforms: (a) 3D stitched cloth fabric, architecture (1); (b) 3D orthogonal woven fabric, architecture (2); (c) needled short-cut felt, architecture (3). Example vertical slice presented in (i) and horizontal slice with a zoomed inset in (ii). The image resolution is $7 \mu \mathrm{m}$ per voxel. A weave defect is identified by "A"

brightest intensity and appears light compared to the darker grey carbon, in which the empty porosity and cracks appear darkest. Enlargements of parts of the tomograph sections, parallel to the $y$-z plane, are presented in Fig. 4a (i), Fig. 4b (i) and Fig. 4c (i). The regions between the $\mathrm{C}$ fiber bundles are almost completely filled by the matrix, and very few cracks and pores are observed. A small number of spherical closed pores (e.g. Figure $4 b$ (i) and Fig. 4c (i)) are observed in the matrix of all the composites. In architecture (1) and (2), interfacial, intra-bundle and matrix cracks can be observed (Fig. 4a (i) and Fig. 4b (i)). Similar cracks have been observed in braided and needled $\mathrm{C} / \mathrm{C}-\mathrm{SiC}$ composites [26, 27], and occur on cooling from the high temperature of the GSI process because of the mismatch of thermal expansion coefficient between the anisotropic arrangement of carbon fiber bundles and matrix. No such cracks are visible in architecture (3), which has a more isotropic fiber distribution.

Images of the composites that were tomographed after the first step of the gravimetric analysis (i.e. acid dissolution) are shown in Fig. 4a (ii), Fig. 4b (ii) and Fig. 4c (ii). The residual $\mathrm{Si}$ has been dissolved, and the distribution of $\mathrm{SiC}$ with respect to the carbon preform can now be readily distinguished. The strong X-ray attenuation contrast difference between $\mathrm{SiC}$ and $\mathrm{C}$ has introduced some tomograph reconstruction artefacts in Fig. $4 \mathrm{~b}$ (ii), which are visible as horizontal dark streaks (in the $x-y$ plane) across the vertical $z$-direction fiber bundles. In both architectures (1) and (2), the SiC tends to be distributed at the surface of the fiber bundles, but there is also some penetration of $\mathrm{SiC}$ into the fiber bundles. The penetration of $\mathrm{SiC}$ into the fiber bundles is particularly obvious in the $z$-direction bundles, which suggests they may be 


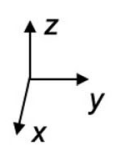

(1)

(a)

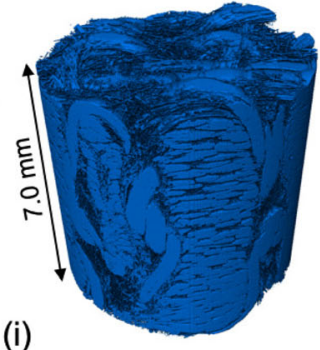

(2)

(b)

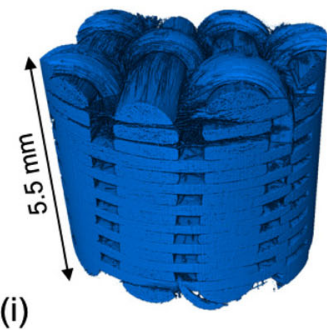

(3)

(c)

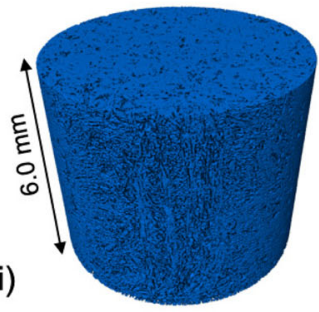

(ii)
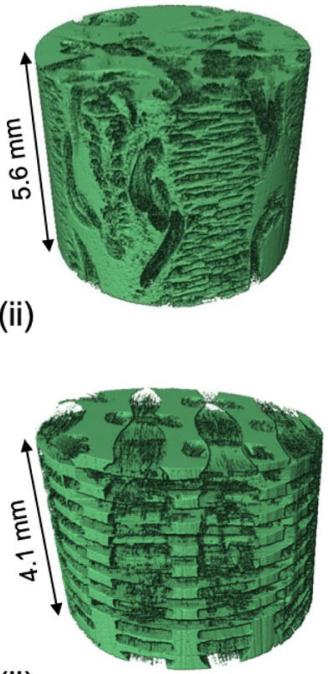

(ii)

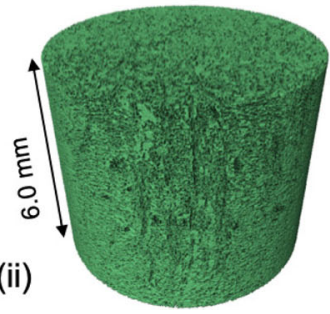

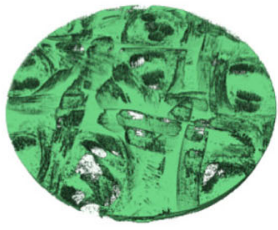

(iii)

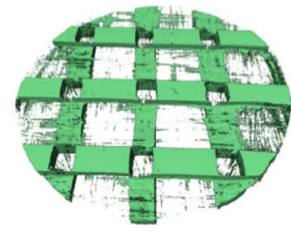

(iii)

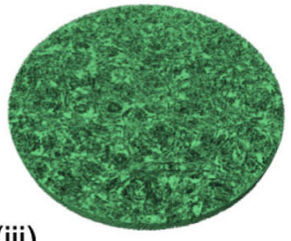

(iii)

Fig. 2 3D visualizations of $\mathrm{C} / \mathrm{C}$ preforms by threshold segmentation of tomographs: (a) 3D stitched cloth fabric, architecture 1); (b) 3D orthogonal woven fabric, architecture (2); (c) needled short-cut felt, architecture (3). The carbon is shown in (i), and the porosity in (ii) (cropped by $0.7 \mathrm{~mm}$ at top and bottom to show internal structure). In (iii), a central subsection of the porosity $(0.42 \mathrm{~mm}$ thickness) is shown

(1)

(2)

(3)

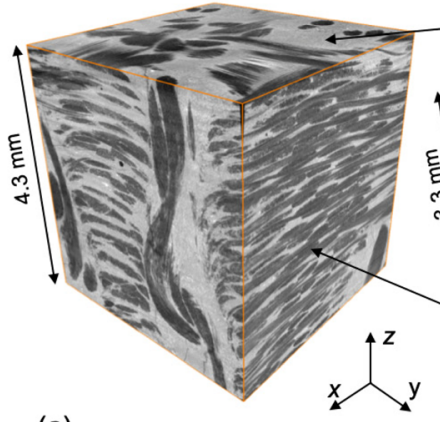

(a)

(b)

(c)

Fig. 3 3D visualizations of the $\mathrm{C} / \mathrm{C}-\mathrm{SiC}$ composites, presented as orthogonal slices of the tomography data: (a) 3D stitched cloth fabric, architecture (1); (b) 3D orthogonal woven fabric, architecture (2); (c) needled short-cut felt, architecture (3) 

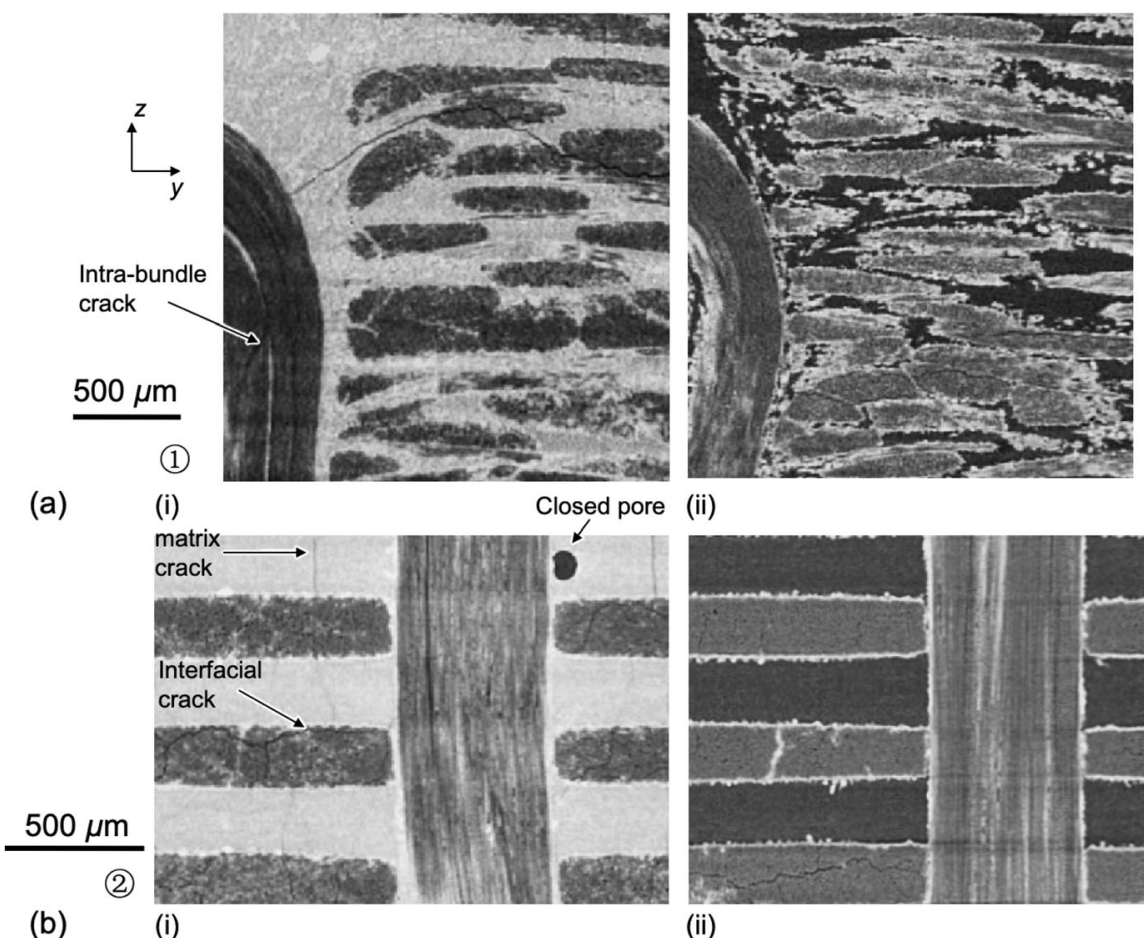

(ii)

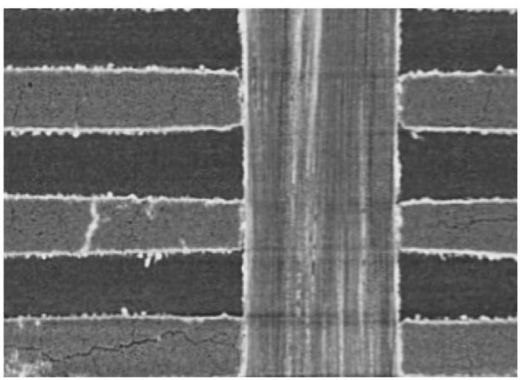

(ii)

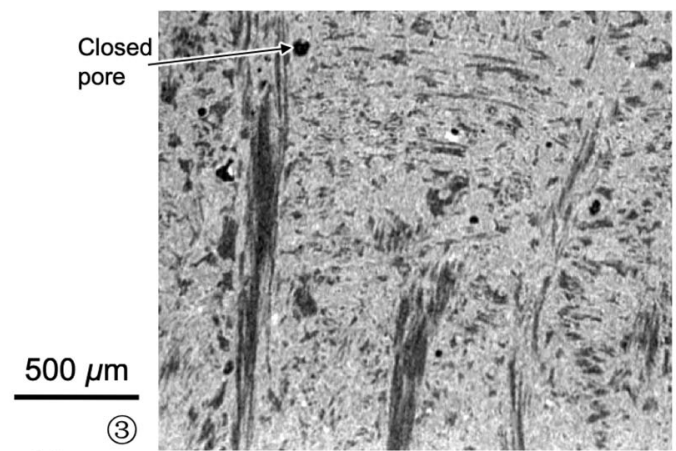

(c)

(i)

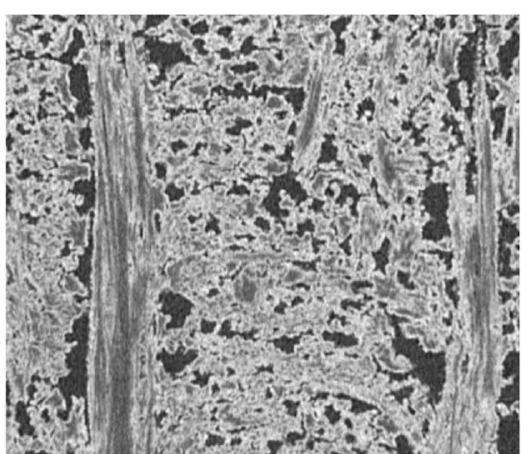

(ii)

Fig. 4 Zoomed images from tomograph slices ( $7 \mu \mathrm{m} /$ voxel) of C/C-SiC composites to show the effects of acid dissolution to remove Si: (a) 3D stitched cloth fabric, architecture (1); (b) 3D orthogonal woven fabric, architecture (2); (c) needled short-cut felt, architecture (3). Typical microstructures (i) before acid dissolution and (ii) after acid dissolution, to indicate intra-bundle, matrix and interfacial cracks, and closed porosity

less compacted than the $x-y$ bundles. Architecture (3) presents the largest amount of SiC after the acid dissolution, compared with the other architectures.

Simple threshold segmentation (Hounsfield greyscale level) was used to label the different phases; $\mathrm{C}$; $\mathrm{SiC}$ and porosity, the latter being representative of the Si that was dissolved by the acid immersion, and these are visualized in Fig. 5. The volume fractions of each segmented phase are in good agreement with the measurements by gravimetric analysis (Table 2). Architecture (3) contains the most $\mathrm{SiC}$, with a content that is almost twice architecture (2) 
(1)

(a)

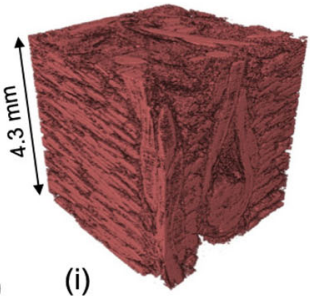

(2)

(b)

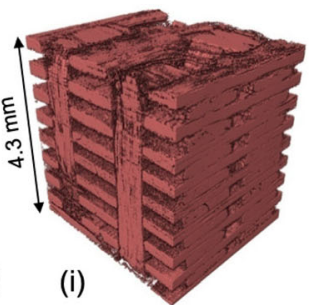

(3)

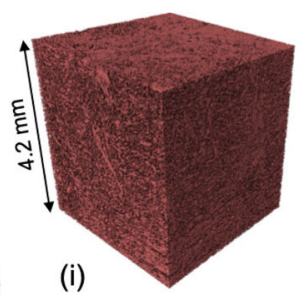

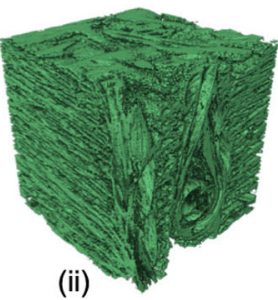

(ii)

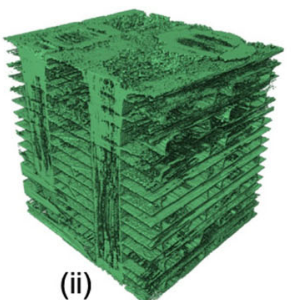

(ii)

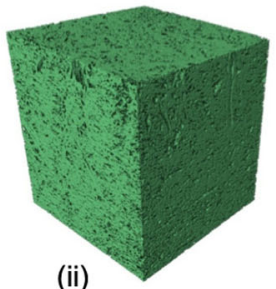

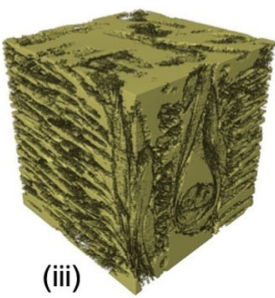

(iii)
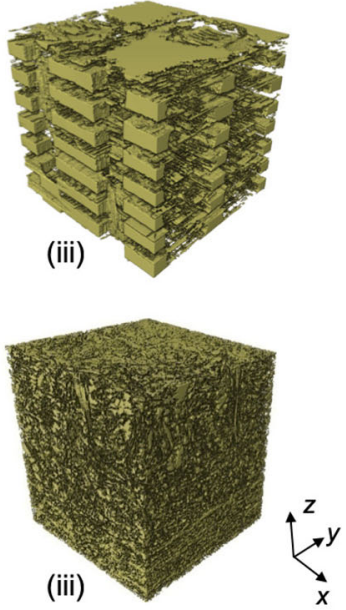

Fig. 5 3D visualizations of $\mathrm{C} / \mathrm{C}-\mathrm{SiC}$ composites, by threshold segmentation of tomographs obtained after acid dissolution to remove Si: (a) 3D stitched cloth fabric, architecture (1); (b) 3D orthogonal woven fabric, architecture (2); (c) needled short-cut felt, architecture (3). The labeled volumes are (i) carbon, (ii) $\mathrm{SiC}$, and (iii) porosity (representing dissolved $\mathrm{Si}$ )

and three times architecture (1). Correspondingly, architecture (3) has retained the least carbon concentration. All microstructures contain a similar fraction of residual silicon (23\% to $30 \%)$.

\subsection{Porosity Analysis}

The total porosities, measured by the gravimetric analysis, are close to $2 \%$ to $3 \%$ in the three composites (Table 2). MIP measures only the open porosity, and this was greatest in architecture (2) $(\sim 3 \%)$, intermediate in architecture (1) (2\%), and lowest in architecture (3) $(\sim 1 \%)$ (Table 2). The open pore size distributions are summarized in Fig. 6a (i), which shows the majority of the open pore volume comprises large pores that are greater than several hundred $\mu \mathrm{m}$ in diameter. Below this size, there is a similar pore size range in all three architectures. The lower porosity measured by MIP in architecture (3) is due to the smaller number of open pores.

Tomography can visualize both open and closed pores, and image segmentation has been used to identify and label the closed pores that were located in the matrix. The distributions of observed closed pores are summarized in Fig. 6a (ii), and visualized in Fig. 6b. The distribution of closed porosity across the pore size range is similar in all three architectures, but the total volume is significantly greater in architecture (3) due to a larger number of pores. Together, the open and closed porosities observed in architectures (1) and (2) are quite 
(a)
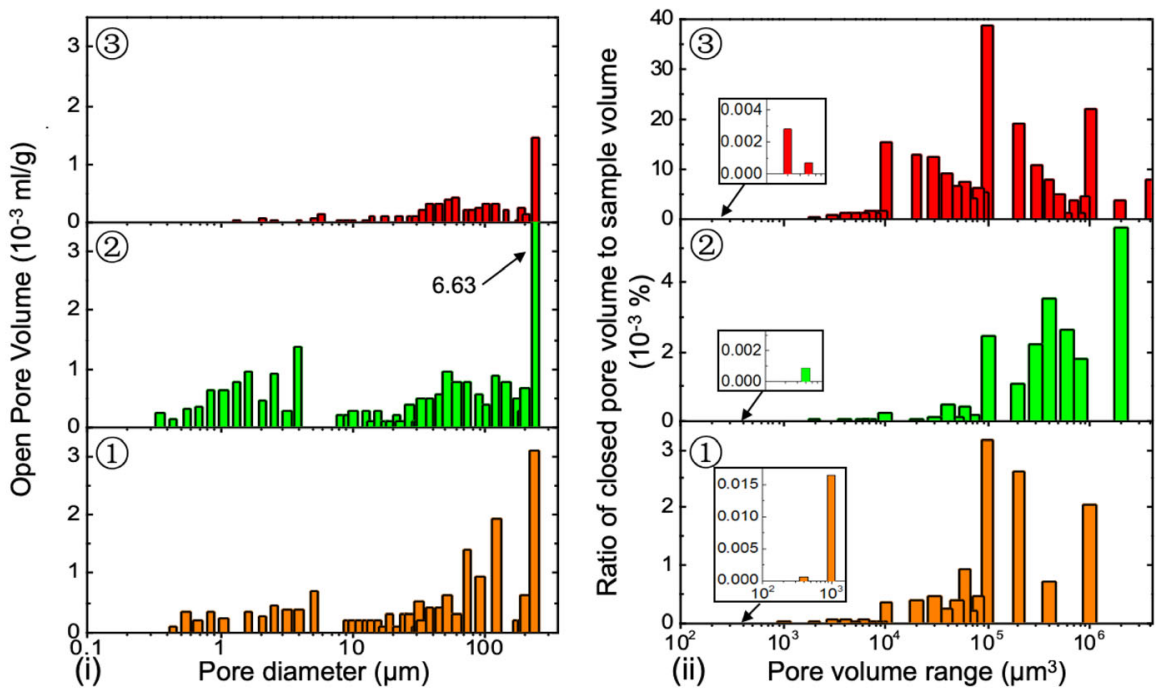

(b)
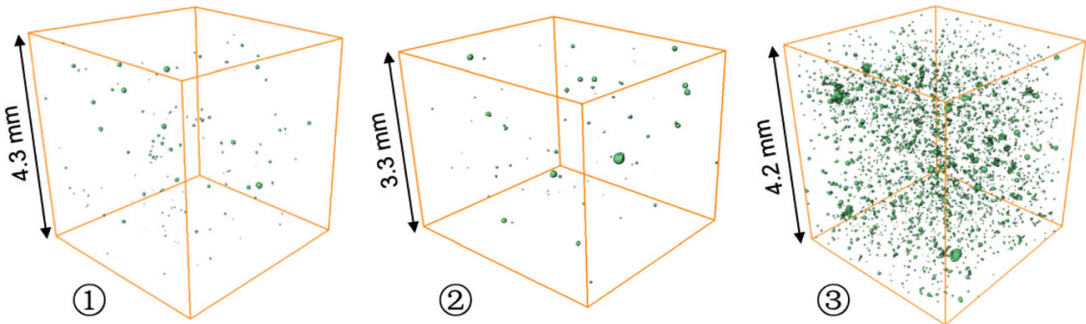

Fig. 6 Analysis of porosity: (a) pore size distributions for (i) open pores detected from MIP and (ii) closed pores observed in matrix by XCT; (b) 3D visualizations of the closed pores in architecture (1) (3D stitched cloth fabric), architecture (2) (3D orthogonal woven fabric) and architecture (3) (needled short-cut felt)

comparable to the total porosity that was measured by the gravimetric analysis. However, although architecture (3) has a significantly greater volume of observed closed porosity than architectures (1) and (2), it is only approximately $0.2 \%$ of the total pore volume that was measured by gravimetric analysis. This indicates that a substantial fraction of closed porosity exists in architecture (3) that is too small to be visualized by XCT at $6 \mu \mathrm{m} /$ voxel resolution (i.e. $\left.<100 \mu \mathrm{m}^{3}\right)$.

\section{Discussion}

The objective of this analysis was to demonstrate the potential of XCT for microstructural characterization in $\mathrm{C} / \mathrm{C}-\mathrm{SiC}$ composites. Conventional ceramographic sample preparation for surface examination risks introducing mechanical damage, and also cannot provide threedimensional information without the use of serial sectioning. Non-destructive XCT allows the observed defects in the microstructure (e.g. Figure 1) to be more reliably attributed to the materials processing. $\mathrm{C} / \mathrm{C}-\mathrm{SiC}$ composites fabricated by silicon infiltration methods will contain a certain amount of residual $\mathrm{Si}$ [8], but this can be difficult to distinguish from $\mathrm{SiC}$ in a ceramographic analysis unless backscatter electron microscopy is used [33]. By incorporating 
non-destructive XCT observations into the gravimetric analysis process, in order to obtain tomographs before and after acid dissolution of silicon, the distribution of $\mathrm{SiC}$ that develops within and on the surfaces of the carbon preform (Fig. 4) can be visualized in 3D (Fig. 5).

$\mathrm{C} / \mathrm{C}$-SiC composites fabricated from different carbon fiber architectures present large differences in density and phase content (Table 2). To obtain best mechanical performance, a spatially continuous and uniform structure of the high strength $\mathrm{SiC}$ matrix is required. For architectures (1) and (2), Fig. 5 shows that the $\mathrm{SiC}$ structures are almost continuous, but is not uniform. Architecture (3) achieved the largest density and produced the most $\mathrm{SiC}$ with a more uniform distribution at the macroscale. This is due to its porous felt structure, which provides the largest contact surface for reaction. This is confirmed in Fig. 4c (ii), which shows the residual $\mathrm{SiC}$ in architecture (3) after acid dissolution to remove the $\mathrm{Si}$; it can be seen that the $\mathrm{SiC}$ tends to form on the surface of the carbon regions, with some penetration between the fiber bundles. Architecture (1) and (2) have large fiber bundles with relative flat surfaces, on which surface layers of $\mathrm{SiC}$ develop that may prevent further reaction from occurring, apart from some limited penetration into the intra-bundle defects within the fiber bundles. This is quite apparent in Fig. 4a (ii) and Fig. 4b (ii).

The level of residual $\mathrm{Si}$ in these composites is high (Table 2). Ideally, there should be complete conversion of $\mathrm{Si}$ to $\mathrm{SiC}$, and the failure to achieve this is attributed to an insufficient reaction with the carbon preform. From comparison of the initial carbon volume fractions (Table 1) with the carbon content in the composite (Table 2), it can be seen that $\sim 18 \%, \sim 11 \%$ and $\sim 28 \%$ of the carbon reacted to form $\mathrm{SiC}$ in architectures (1), (2) and (3), respectively. The $\mathrm{CVI} \mathrm{PyC}$ is critical to form a continuous $\mathrm{SiC}$ structure and to prevent the carbon fiber preform from being eroded, especially for the $z$-direction fiber bundles. However, prolonged infiltration by CVI may close the small pore throats that are located at the junctions of the fiber bundles and are the connecting passages of the large pores, such as those in architecture (2) (Fig. 2). This will prevent further infiltration to develop PyC and will produce closed voids [34], and it will also affect the penetration of Si during the GSI process. Alternative methods, such as Precursor Impregnation and Pyrolysis (PIP), which can produce a more porous carbon matrix [35, 36] may accordingly be more suitable for architecture (1) and (2) to improve their SiC content.

The architecture of carbon fiber preforms also has a strong impact on the pore distributions of $\mathrm{C} / \mathrm{C}-\mathrm{SiC}$ composites. The total porosity is low, and the significant difference (Table 2) between the total porosity measured by GA and that detected by XCT (closed pore) and MIP (open pore) is because the closed porosity comprises very small pores in the matrix and also within the fiber bundles that are below the resolution limit of the tomography. The closed pores located in the matrix (Fig. 4) are not significant to the material performance. However, intra-bundle pores that are in the carbon preform, which may be closed or open, can be detrimental to material performance. Closed intra-bundle pores can initiate cracks under mechanical loading [25], while open intra-bundle pores, which may be continuous, will act as a transport path for oxidation and may offset the beneficial effects of $\mathrm{SiC}$ to ablation resistance [37]. The microstructure characteristics and the proportion and distribution of open pores in architecture (3) indicate that it would be expected to have better oxidation-resistance than architectures (1) and (2).

\section{Conclusions}

$\mathrm{X}$-ray computed tomography $(\mathrm{XCT})$ has been used to observe the microstructure morphologies of three types of $\mathrm{C} / \mathrm{C}$ preforms and the $\mathrm{C} / \mathrm{C}-\mathrm{SiC}$ composites fabricated from them by 
Gaseous Silicon Infiltration (GSI). The preform architectures are observed to strongly influence the material composition and phase distribution. In particular the spatial connection of $\mathrm{SiC}$ is affected by the amount of free surface of carbon, and the amount of conversion of carbon to $\mathrm{SiC}$ by $\mathrm{Si}$ is affected by the CVI penetration into the preform to form PyC. The information obtained by $3 \mathrm{D}$ characterization of microstructure by XCT provides insights into the likely mechanical and oxidation properties of the composite.

Acknowledgements We acknowledge EPSRC Grant EP/M02833X/1 "University of Oxford: experimental equipment upgrade" that supported the Xradia Versa 510 microscope and facilities for data analysis and visualization. The research is part of the Project 2018JJ1029 supported by Hunan Provincial Natural Science Foundation of China. The research data supporting this publication can be accessed by contacting the corresponding author.

Open Access This article is distributed under the terms of the Creative Commons Attribution 4.0 International License (http://creativecommons.org/licenses/by/4.0/), which permits unrestricted use, distribution, and reproduction in any medium, provided you give appropriate credit to the original author(s) and the source, provide a link to the Creative Commons license, and indicate if changes were made.

\section{References}

1. Patel, M., Saurabh, K., Prasad, V.B., Subrahmanyam, J.: High temperature C/C-SiC composite by liquid silicon infiltration: a literature review. Bull. Mater. Sci. 35, 67-77 (2012). https://doi.org/10.1007/s12034011-0247-5

2. Krenkel, W., Berndt, F.: C/C-SiC composites for space applications and advanced friction systems. Mater. Sci. Eng. A. 412, 177-181 (2005). https://doi.org/10.1016/j.msea.2005.08.204

3. Li, T., Yu, X., Liu, H., Yang, H., Li, Y.: Tensile behavior of C/SiC composites plate after hypervelocity penetration: residual strength and fracture mechanism. Compos. Struct. 189, 378-385 (2018). https://doi. org/10.1016/j.compstruct.2018.01.058

4. Chen, Z., Fang, G., Xie, J., Liang, J.: Experimental study of high-temperature tensile mechanical properties of 3D needled C/C-SiC composites. Mater. Sci. Eng. A. 654, 271-277 (2016). https://doi.org/10.1016/j. msea.2015.12.010

5. Yang, C.P., Zhang, L., Wang, B., Huang, T., Jiao, G.Q.: Tensile behavior of 2D-C/SiC composites at elevated temperatures: experiment and modeling. J. Eur. Ceram. Soc. 37, 1281-1290 (2017). https://doi. org/10.1016/j.jeurceramsoc.2016.11.011

6. Dong, Z.J., Liu, S.X., Li, X.K., Westwood, A., Yuan, G.M., Cui, Z.W., Cong, Y.: Influence of infiltration temperature on the microstructure and oxidation behavior of $\mathrm{SiC}-\mathrm{ZrC}$ ceramic coating on $\mathrm{C} / \mathrm{C}$ composites prepared by reactive melt infiltration. Ceram. Int. 41, 797-811 (2014). https://doi.org/10.1016/j. ceramint.2014.08.138

7. Cui, Y., Li, A., Li, B., Ma, X., Bai, R., Zhang, W., Ren, M., Sun, J.: Microstructure and ablation mechanism of C/C-SiC composites. J. Eur. Ceram. Soc. 34, 171-177 (2014). https://doi.org/10.1016/j. jeurceramsoc.2013.08.026

8. Zhou, X., Zhu, D., Xie, Q., Luo, F., Zhou, W.: Friction and wear properties of C/C-SiC braking composites. Ceram. Int. 38, 2467-2473 (2012). https://doi.org/10.1016/j.ceramint.2011.11.015

9. Qian, Y., Zhang, W., Ge, M., Wei, X.: Frictional response of a novel C/C-ZrB $2-\mathrm{ZrC}-\mathrm{SiC}$ composite under simulated braking. J. Adv. Ceram. 2, 157-161 (2013). https://doi.org/10.1007/s40145-013-0055-Z

10. Nie, J., Xu, Y., Zhang, L., Yin, X., Cheng, L., Ma, J.: Effect of stitch spacing on mechanical properties of carbon / silicon carbide composites. Compos. Sci. Technol. 68, 2425-2432 (2008). https://doi.org/10.1016/j. compscitech.2008.04.012

11. Zhang, Y., Xiao, Z., Wang, J., Yang, J., Jin, Z.: Effect of pyrocarbon content in C/C preforms on microstructure and mechanical properties of the $\mathrm{C} / \mathrm{C}-\mathrm{SiC}$ composites. Mater. Sci. Eng. A. 502, 64-69 (2009). https://doi.org/10.1016/j.msea.2008.11.026

12. Wang, H., Zhu, D., Wan, F., Zhou, W., Luo, F.: Influence of the C/C preform density on tribological characteristics of $\mathrm{C} / \mathrm{C}-\mathrm{SiC}$ composites under different conditions. Ceram. Int. 40, 16641-16646 (2014). https://doi.org/10.1016/j.ceramint.2014.08.025 
13. Forsberg, F., Sjo, M., Mooser, R., Hack, E., Wyss, P.: Full three-dimensional strain measurements on wood exposed to three-point bending: analysis by use of digital volume correlation applied to synchrotron radiation micro-computed tomography image data. Strain. 46, 47-60 (2010). https://doi.org/10.1111 /j.1475-1305.2009.00687.x

14. Yang, Z., Ren, W., Sharma, R., McDonald, S., Mostafavi, M., Vertyagina, Y., Marrow, T.J.: In-situ X-ray computed tomography characterisation of 3D fracture evolution and image-based numerical homogenisation of concrete. Cem. Concr. Compos. 75, 74-83 (2017). https://doi.org/10.1016/j. cemconcomp.2016.10.001

15. Kong, L., Ostadhassan, M., Li, C., Tamimi, N.: Pore characterization of 3D-printed gypsum rocks: a comprehensive approach. J. Mater. Sci. 53, 5063-5078 (2018). https://doi.org/10.1007/s10853-017-1953-1

16. Marrow, T.J., Liu, D., Barhli, S.M., Saucedo Mora, L., Vertyagina, Y., Collins, D.M., Reinhard, C., Kabra, S., Flewitt, P.E.J., Smith, D.J.: In situ measurement of the strains within a mechanically loaded polygranular graphite. Carbon. 96, 285-302 (2016). https://doi.org/10.1016/j.carbon.2015.09.058

17. Barhli, S.M., Saucedo-Mora, L., Jordan, M.S.L., Cinar, A.F., Reinhard, C., Mostafavi, M., Marrow, T.J.: Synchrotron X-ray characterization of crack strain fields in polygranular graphite. Carbon. 124, 357-371 (2017). https://doi.org/10.1016/j.carbon.2017.08.075

18. Shen, H., Nutt, S., Hull, D.: Direct observation and measurement of fiber architecture in short fiber-polymer composite foam through micro-CT imaging. Compos. Sci. Technol. 64, 2113-2120 (2004). https://doi. org/10.1016/j.compscitech.2004.03.003

19. Chateau, C., Gélébart, L., Bornert, M., Crépin, J., Boller, E., Sauder, C., Ludwig, W.: In situ X-ray microtomography characterization of damage in $\mathrm{SiC} f / \mathrm{SiC}$ minicomposites. Compos. Sci. Technol. 71, 916-924 (2011). https://doi.org/10.1016/j.compscitech.2011.02.008

20. Bale, H.A., Haboub, A., Macdowell, A.A., Nasiatka, J.R., Parkinson, D.Y., Cox, B.N., Marshall, D.B., Ritchie, R.O.: Real-time quantitative imaging of failure events in materials under load at temperatures above $1,600^{\circ}$ C. Nat. Mater. 12, 40-46 (2013). https://doi.org/10.1038/nmat3497

21. Melenka, G.W., Lepp, E., Cheung, B.K.O., Carey, J.P.: Micro-computed tomography analysis of tubular braided composites. Compos. Struct. 131, 384-396 (2015). https://doi.org/10.1016/j. compstruct.2015.05.057

22. Zou, C., Marrow, T.J., Reinhard, C., Li, B., Zhang, C., Wang, S.: Porosity characterization of fiberreinforced ceramic matrix composite using synchrotron X-ray computed tomography. J. Instrum. 11, C03052 (2016)

23. Saucedo-Mora, L., Zou, C., Lowe, T., Marrow, T.J.: Three-dimensional measurement and cohesive element modelling of deformation and damage in a 2.5-dimensional woven ceramic matrix composite. Fatigue Fract. Eng. Mater. Struct. 40, 683-695 (2017). https://doi.org/10.1111/ffe.12537

24. Hausherr, J.M., Krenkel, W.: Nondestructive characterization of high-performance C / SiC-ceramics using X-ray-computed tomography. Int. J. Appl. Ceram. Technol. 7, 361-368 (2010). https://doi.org/10.1111 /j.1744-7402.2009.02449.x

25. Wan, F., Zhao, S., Liu, R., Zhang, C., Marrow, T.J.: In situ observation of compression damage in a threedimensional braided carbon Fiber reinforced carbon and silicon carbide (C/C-SiC) ceramic composite. Microsc. Microanal. 24, 227-237 (2018). https://doi.org/10.1017/S1431927618000351

26. Wan, F., Liu, R., Wang, Y., Cao, Y., Zhang, C., James, T.: In situ observation of compression damage in a 3D needled-punched carbon fiber-silicon carbide ceramic matrix composite. Compos. Struct. 210, 189-201 (2019). https://doi.org/10.1016/j.compstruct.2018.11.041

27. Wan, F., Liu, R., Wang, Y., Cao, Y., Zhang, C., James, T.: Damage development during flexural loading of a 5-directional braided $\mathrm{C} / \mathrm{C}$ - $\mathrm{SiC}$ composite , characterized by X-ray tomography and digital volume correlation. Ceram. Int. 45, 5601-5612 (2019). https://doi.org/10.1016/j.ceramint.2018.12.020

28. Saucedo-Mora, L., Marrow, T.J.: Multi-scale damage modelling in a ceramic matrix composite using a finite-element microstructure meshfree methodology. Philos. Trans. R. Soc. A Math. Phys. Eng. Sci. 374, 20150276 (2016). https://doi.org/10.1098/rsta.2015.0276

29. Liu, S., Zhang, L., Yin, X., Cheng, L., Liu, Y.: Microstructure and mechanical properties of SiC and carbon hybrid Fiber reinforced SiC matrix composite. Int. J. Appl. Ceram. Technol. 8, 308-316 (2011). https://doi. org/10.1111/j.1744-7402.2010.02588.x

30. Yan, C., Liu, R., Zhang, C., Cao, Y.: Effect of PyC interphase thickness on mechanical and ablation properties of 3D C f/ ZrC - SiC composite. Ceram. Int. 42, 12756-12762 (2016). https://doi.org/10.1016/j. ceramint.2016.04.187

31. Huang, L., Liu, R.J., Zhang, C., Wang, Y., Cao, Y.: Si/SiC optical coatings for C/SiC composites via gelcasting and gas silicon infiltration: effects of carbon black content. J. Alloys Compd. 711, 162-168 (2017). https://doi.org/10.1016/j.jallcom.2017.03.222 
32. Nie, J., Xu, Y., Zhang, L., Fan, S., Xu, F., Cheng, L., Ma, J., Yin, X.: Microstructure, thermophysical, and ablative performances of a 3D needled C/C-SiC composite. Int. J. Appl. Ceram. Technol. 7, 197-206 (2010). https://doi.org/10.1111/j.1744-7402.2008.02341.x

33. Schulte-Fischedick, J., Zern, A., Mayer, J., Rühle, M., Frieß, M., Krenkel, W., Kochendörfer, R.: The morphology of silicon carbide in C/C-SiC composites. Mater. Sci. Eng. A. 332, 146-152 (2002). https://doi. org/10.1016/S0921-5093(01)01719-1

34. Granda, M., Patrick, J.W., Walker, A., Casal, E., Bermejo, J., Menendez, R.: Densification of unidirectional $\mathrm{C} / \mathrm{C}$ composites by melted pitch impregnation. Carbon. 36, 943-952 (1998)

35. Fitzer, E., Hüttner, W., Manocha, L.M.: Influence of process parameters on the mechanical properties of carbon_carbon-composites with pitch as matrix precursor. Carbon. 18, 291-295 (1980)

36. Kanno, K., Fernandez, J.J., Fortin, F., Korai, Y., Mochida, I.: Modifications to carbonization of mesophase pitch by addition of carbon blacks. Carbon. 35, 1627-1637 (1997)

37. Liu, L., Li, H., Hao, K., Shi, X., Li, K., Ni, C.: Effect of SiC location on the ablation of C/C-SiC composites in two heat fluxes. J. Mater. Sci. Technol. 31, 345-354 (2015). https://doi.org/10.1016/j.jmst.2014.11.021

Publisher's Note Springer Nature remains neutral with regard to jurisdictional claims in published maps and institutional affiliations. 